\title{
Ambulatory veno-venous extracorporeal membrane oxygenation: Innovation and pitfalls
}

\author{
Jose P. Garcia, MD, ${ }^{a}$ Zachary N. Kon, $\mathrm{MD},{ }^{\mathrm{a}}$ Charles Evans, $\mathrm{MD},{ }^{\mathrm{a}}$ Zhongjun $\mathrm{Wu}, \mathrm{PhD},{ }^{\mathrm{a}}$ \\ Aldo T. Iacono, MD, ${ }^{\mathrm{b}}$ Brian McCormick, CPP, ${ }^{\mathrm{a}}$ and Bartley P. Griffith, MD ${ }^{\mathrm{a}}$
}

\begin{abstract}
Objective: End-stage lung disease and severe acute lung injury are complex entities that remain challenges to manage. Therapies include early institution of mechanical ventilation with positive end-expiratory pressure, permissive hypercapnia, pulmonary vasodilators, and complex fluid regimens. Veno-venous extracorporeal membrane oxygenation is an available treatment option for these patients but, in its conventional form, can be associated with significant complications. We present our early experience with an attempt to optimize extracorporeal membrane oxygenation, emphasizing reduced adjunctive mechanical ventilatory support and aggressive rehabilitation, with a goal of ambulation. This strategy has been enabled by the introduction of a dual-lumen draw and return cannula placed via the internal jugular vein.
\end{abstract}

Methods: The first 10 patients (mean age of 45.3 years, 8 male) treated with this strategy between January 1 , 2009 , and October 1, 2009, were retrospectively reviewed. The ambulatory extracorporeal membrane oxygenation strategy was initiated with an aim of minimal mechanical ventilation and aggressive rehabilitation. The patients were intended to be weaned from all respiratory support or bridged to transplantation.

Results: The mean duration of extracorporeal membrane oxygenation was 20 (9-59) days, with average mean blood flows of 3.5 (1.6-4.9) L/min, and levels of $\mathrm{CO}_{2}$ removal and $\mathrm{O}_{2}$ transfer of $228(54-570) \mathrm{mL} / \mathrm{min}$ and 127 (36-529) $\mathrm{mL} / \mathrm{min}$, respectively. Six of 10 patients were weaned from respiratory support $(\mathrm{N}=4)$ or underwent transplantation $(\mathrm{N}=2)$ and survived to discharge from the hospital. The remaining 4 patients died of sepsis $(\mathrm{N}=3)$ and withdrawal of care after renal failure $(\mathrm{N}=1)$. Four of the 6 surviving patients were extubated and ambulatory while still on extracorporeal membrane oxygenation. During that time, 3 of the 4 patients exercised at the bedside, with the remaining patient able to undergo full cardiopulmonary rehabilitation, including treadmill walking.

Conclusions: Improvements in the durability of membrane blood oxygenators and pumps have prompted renewed consideration of extracorporeal membrane oxygenation in patients with severe lung disease. This report describes an attempt to augment extracorporeal membrane oxygenation with the goal of ambulation by minimizing mechanical ventilatory support and using aggressive in-and-out-of-bed rehabilitation. (J Thorac Cardiovasc Surg 2011;142:755-61)

End-stage chronic lung disease and severe acute lung injury are challenging to manage. Therapies include early institution of mechanical ventilation (MV) with positive endexpiratory pressure, permissive hypercapnia, pulmonary vasodilators, and complex fluid regimens. ${ }^{1,2}$

Veno-venous (VV) extracorporeal membrane oxygenation (ECMO) has been used in nonresponsive patients with some promising results ${ }^{3-6}$; however, there are significant limitations associated with its current implementation.

From the Divisions of Cardiac Surgery ${ }^{\mathrm{a}}$ and Pulmonary Medicine, ${ }^{\mathrm{b}}$ University of Maryland School of Medicine, Baltimore, Md.

Disclosures: Authors have nothing to disclose with regard to commercial support.

Read at the 91st Annual Meeting of The American Association for Thoracic Surgery, Philadelphia, Pennsylvania, May 7-11, 2011.

Received for publication July 14, 2010; revisions received July 8, 2011; accepted for publication July 19, 2011.

Address for reprints: Jose P. Garcia, MD, Division of Cardiac Surgery, University of Maryland School of Medicine, 22 S Baltimore, MD 21201, Greene Street, N4W94

(E-mail: jgarcia@smail.umaryland.edu).

$0022-5223 / \$ 36.00$

Copyright (C) 2011 by The American Association for Thoracic Surgery

doi:10.1016/j.jtcvs.2011.07.029
Conventional ECMO requires cannulation of at least 1 femoral vessel, necessitating immobilization and physical deconditioning. Patients receiving ECMO have seldom been weaned from $\mathrm{MV}$, increasing the risk of ventilatorassociated pneumonia and ventilator-induced lung injury, even with minimal pressure/volume protocols.

With the recent development of a dual-lumen single ECMO cannula, ECMO can be instituted via only right internal jugular (IJ) cannulation. Using this approach, we have attempted to improve outcomes by minimizing mechanical ventilatory support and maximizing mobilization and rehabilitation. We report our initial experience and lessons learned from the implementation of this strategy.

\section{MATERIALS AND METHODS \\ Patient Selection}

The first 10 consecutive patients treated using an ambulatory ECMO strategy were retrospectively reviewed with institutional review board approval (HP-00044921). Patient selection was done in collaboration with the intensive care unit (ICU) and cardiac surgery teams. Enrollment criteria 


$$
\begin{aligned}
& \text { Abbreviations and Acronyms } \\
& \text { COPD }=\text { chronic obstructive pulmonary disease } \\
& \text { ECMO }=\text { extracorporeal membrane oxygenation } \\
& \text { ICU }=\text { intensive care unit } \\
& \text { IJ } \quad \text { internal jugular } \\
& \text { IPF }=\text { idiopathic pulmonary fibrosis } \\
& \text { MV }=\text { mechanical ventilation } \\
& \text { PAH }=\text { pulmonary arterial hypertension } \\
& \text { VV }=\text { veno-venous }
\end{aligned}
$$

were severe respiratory failure despite maximal conventional therapy or MV requirement with a disease process that has previously yielded greater than $90 \%$ mortality once requiring MV (ie, idiopathic pulmonary fibrosis [IPF]) (Table 1). Excluded were patients with a nonreversible disease process, who were thought to be nontransplant candidates, or who had a body surface area greater than $2.0 \mathrm{~m}^{2}$. Pre-ECMO physiologic, hemodynamic, and ventilator variables are shown in Table 2 .

\section{Cannulation for Extracorporeal Membrane Oxygenation}

Patients were transferred to the controlled environment of the operating room and placed onto a fluoroscopic-enabled operating table. To allow for mobilization while on ECMO, femoral cannulation was avoided. A duallumen Avalon cannula (Avalon Laboratories, LLC, Rancho Dominguez, Calif) was placed via the right IJ for both inflow from the superior and inferior venae cavae and outflow to the mid-right atrium, as previously described. ${ }^{7}$ Under general anesthesia, the IJ was localized with sonographic guidance and a right $\mathrm{IJ}$ venopuncture was made with a $5 \mathrm{~F}$ micropuncture needle (Cook Medical Inc, Bloomington, Ind). Over a guidewire, a 5F Kumpe catheter (Cook Medical Inc) was then introduced and positioned with the distal radiopaque tip extending $2 \mathrm{~cm}$ into the inferior vena cava with transesophageal echocardiography and fluoroscopic guidance and confirmation. In our first 2 patients, we created a 3- to 5-cm tunnel anterior to the clavicle in the subcutaneous plane to an infraclavicular exit site. Because of mild kinking of the cannula at the bend, a more gentle and ergonomically improved supraclavicular exit site was used in subsequent patients $(\mathrm{N}=8)$. The length of the tunnel was measured to allow the "Y" of the dual-lumen cannula to sit at the exit site for long-term position stability. The soft guide wire was then exchanged for an Amplatz stiff wire (Cook Medical Inc), and sequential dilation of the venous access was completed. The Avalon cannula (Avalon Laboratories, LLC) was positioned over the wire with the ECMO inflow lumen fenestrations sitting in the superior and inferior venae cavae, and the outflow to the mid-right atrium toward the tricuspid valve (Figure 1). The cannula was connected to a crystalloid primed ECMO circuit, including a CentriMag pump (Levitronix, Boston, Mass) and Quadrox oxygenator (Maquet Cardiovascular LLC, San Jose, Calif). The system and oxygen tank were mounted to a wheeled intravenous pole to facilitate patient mobility (Figure 2).

\section{Mechanical Ventilation Management}

Given the ability of the VV-configured ECMO to manage $\mathrm{PCO}_{2}$, primary reference for weaning from $\mathrm{MV}$ was $\mathrm{S}_{\mathrm{AO}_{2}}$. $\mathrm{FIO}_{2}$ and positive end-expiratory pressure were titrated to an oxygen saturation of $85 \%$ or greater. For consideration of extubation, the patient needed to be awake and cooperative. However, other standard evaluation variables, including $\mathrm{PCO}_{2}$, negative inspiratory force, tidal volumes, and rapid shallow breathing index were deemphasized to qualify for extubation. In patients in whom an extended wean from $\mathrm{MV}$ was expected because of low $\mathrm{SAO}_{2}$, or if significant
TABLE 1. Patient characteristics

\begin{tabular}{lclll}
\hline Patient no. & Age $(\mathbf{y})$ & Gender & BMI & \multicolumn{1}{c}{ Diagnosis } \\
\hline 1 & 31 & Male & 29.34 & Pneumonia/ARDS \\
2 & 49 & Male & 22.14 & COPD \\
3 & 67 & Male & 35.96 & IPF \\
4 & 25 & Female & 24.41 & Pneumonia/ARDS \\
5 & 62 & Male & 33.28 & IPF \\
6 & 56 & Male & 34.89 & IPF \\
7 & 39 & Male & 33.66 & Pneumonia/ARDS \\
8 & 56 & Male & 26.14 & pneumonia/ARDS \\
9 & 31 & Male & 28.86 & IPF \\
10 & 35 & Female & 18.23 & PAH/RVF \\
\hline BMI, Body mass index; ARDS, acute respiratory distress & syndrome; $R V F$, right \\
ventricular failure. & & &
\end{tabular}

pulmonary secretions were present making pulmonary toilet difficult, an early, open tracheostomy was performed. If extubation was not immediately possible, full ECMO support was used with minimal MV support (ARDSNet protocol was used).

\section{Extracorporeal Membrane Oxygenation Management}

Anticoagulation and blood product transfusions. Heparin was used for anticoagulation with a target activated clotting time of 160 to 180 seconds. If heparin-induced thrombocytopenia and thrombosis was evident, argatroban was used with an activated partial thromboplastin time goal of 2 to 2.5 times normal. To optimize oxygen-carrying capacity, patients were transfused with packed red blood cells to maintain a hematocrit of at least $35 \%$ as a trigger, with a goal of $40 \%$. Platelet transfusion was reserved for a count of 20,000 or less or active bleeding to avoid sensitization to human leukocyte antigen should the patient be or become a candidate for transplant.

\section{Extracorporeal Membrane Oxygenation Support and Weaning}

Pump speed was titrated to maintain the highest flow return to ensure $\mathrm{S}_{\mathrm{AO}}$ with a maximum measured inflow negative pressure of $85 \mathrm{~mm} \mathrm{Hg}$ or less. For patients with reversible lung disease, intended as a bridge to recovery, ECMO was weaned when clinically appropriate as determined by both the ICU and cardiac surgery teams. The ECMO $\mathrm{FIO}_{2}$ was gradually turned down to 0.21 for 2 hours. When successful, the sweep was then turned off for an additional 2 hours, allowing complete recirculation. If adequate oxygenation and ventilation were maintained, ECMO decannulation was performed. The patient was placed in the Trendelenburg position to decrease risk air embolism, a single 0 silk $U$ stitch was placed, and the cannula was pulled at the bedside. For patients qualifying for lung transplantation with nonreversible disease processes, full ECMO support was continued until transplantation.

\section{Data Collection}

Data were collected from electronic medical records, critical care flowsheets, ventilator flowsheets, and perfusion flowsheets. Pre-ECMO MV settings are the last ventilator settings recorded on the critical care flowsheet before the ECMO circuit was initiated.

\section{RESULTS}

\section{Extracorporeal Membrane Oxygenation Variables}

A smaller dual-lumen cannula $(23 \mathrm{~F})$ was used for patients $(\mathrm{N}=2)$ with primarily hypercapnea, who required 
TABLE 2. Pre-extracorporeal membrane oxygenation patient variables

\begin{tabular}{|c|c|c|c|c|c|c|c|c|c|c|c|c|}
\hline \multirow[b]{2}{*}{ Patient no. } & \multicolumn{3}{|c|}{ ABG } & \multicolumn{3}{|c|}{ Mechanical ventilation } & \multicolumn{3}{|c|}{ Adjunct therapies } & \multicolumn{3}{|c|}{ Hemodynamic stability } \\
\hline & $\mathbf{P A O}_{2}$ & $\mathrm{PCO}_{2}$ & pH & Duration & $\mathrm{FIO}_{2}$ & PEEP & Nitric oxide & Steroids & Paralysis & Pressors & $\begin{array}{c}\text { SBP } \\
<90 \mathrm{~mm} \mathrm{Hg}\end{array}$ & $\begin{array}{c}\text { RV } \\
\text { dysfunction }\end{array}$ \\
\hline 1 & 32 & 89 & 7.30 & 6 & 1.0 & $*$ & Y & $\mathrm{Y}$ & $\mathrm{Y}$ & $\mathrm{Y}$ & Y & $\mathrm{N}$ \\
\hline 2 & 89 & 75 & 7.39 & 15 & 0.6 & 5 & Y & Y & Y & Y & $\mathrm{N}$ & $\mathrm{N}$ \\
\hline 3 & 93 & 79 & 7.35 & 6 & 0.7 & 10 & $\mathrm{Y}$ & Y & $\mathrm{N}$ & $\mathrm{Y}$ & Y & Y \\
\hline 4 & 82 & 45 & 7.31 & 16 & 1.0 & $\dagger$ & Y & $\mathrm{Y}$ & Y & $\mathrm{Y}$ & Y & $\mathrm{N}$ \\
\hline 5 & 154 & 59 & 7.39 & 4 & 0.7 & 8 & Y & Y & $\mathrm{N}$ & $\mathrm{Y}$ & Y & Y \\
\hline 6 & 51 & 60 & 7.43 & 3 & 1.0 & * & $\mathrm{Y}$ & $\mathrm{N}$ & $\mathrm{Y}$ & $\mathrm{Y}$ & $\mathrm{Y}$ & $\mathrm{Y}$ \\
\hline 7 & 41 & 86 & 7.23 & 38 & 1.0 & 15 & Y & $\mathrm{N}$ & $\mathrm{N}$ & Y & Y & $\mathrm{N}$ \\
\hline 8 & 108 & 63 & 7.28 & 5 & 0.6 & 12 & Y & Y & $\mathrm{N}$ & Y & Y & $\mathrm{N}$ \\
\hline 9 & 54 & 67 & 7.33 & 6 & 0.8 & 5 & Y & $\mathrm{Y}$ & Y & Y & Y & Y \\
\hline 10 & 49 & 23 & 7.45 & 1 & 1.0 & * & Y & Y & $\mathrm{N}$ & Y & Y & Y \\
\hline
\end{tabular}

PEEP, Positive end-expiratory pressure; $S B P$, systolic blood pressure; $R V$, right ventricular. *Patient on airway pressure release ventilation. $\dagger$ Patient on high-frequency oscillator.

lower blood flows (Table 3). Larger 31F cannulae were used for patients with severe hypoxia, who required higher flows. Initially, we attempted to use a $29 \mathrm{~F}$ cannula, but were limited to a mean flow of $3.3(3.2-3.5) \mathrm{L} / \mathrm{min}$, and thus a mean $\mathrm{O}_{2}$ transport of $115(53-193) \mathrm{mL} / \mathrm{min}$. Subsequently, the $31 \mathrm{~F}$ cannulae became our size of choice for patients with high oxygen transfer requirements. The rates of blood flow averaged $3.5(1.6-4.9) \mathrm{L} / \mathrm{min}$ in this series. Rates of
$\mathrm{O}_{2}$ transfer and $\mathrm{CO}_{2}$ removal were $127(36-529) \mathrm{mL} / \mathrm{min}$ and $228(54-570) \mathrm{mL} / \mathrm{min}$, respectively. The duration of ECMO was $20 \pm 15$ days.

\section{Outcomes}

Six of the 10 patients were successfully weaned from MV while still on ECMO (Table 4). Four of the 6 patients required tracheostomy for a slower wean and assistance

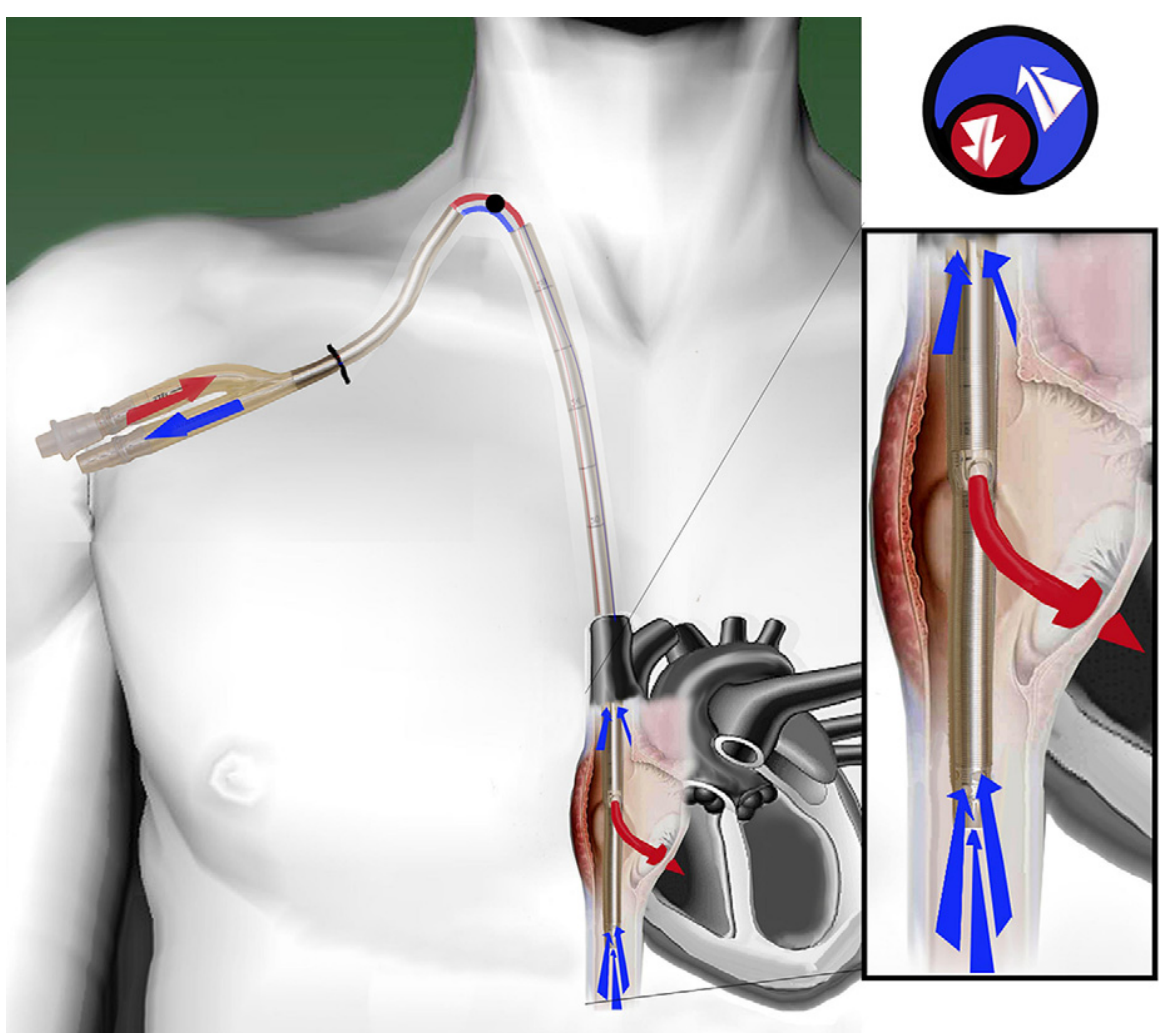

FIGURE 1. Insertion of the dual-lumen cannula into the IJ vein via tunneling from the right subclavicular chest (supraclavicular tunneling not shown). Note the subtle curve of the tunneled cannula. Inflow to the ECMO circuit is from the tip of the cannula located in the inferior vena cava and fenestrations in the mid-cannula at the superior vena cava-right atrial junction. Outflow between these 2 points is directed at the tricuspid valve. 


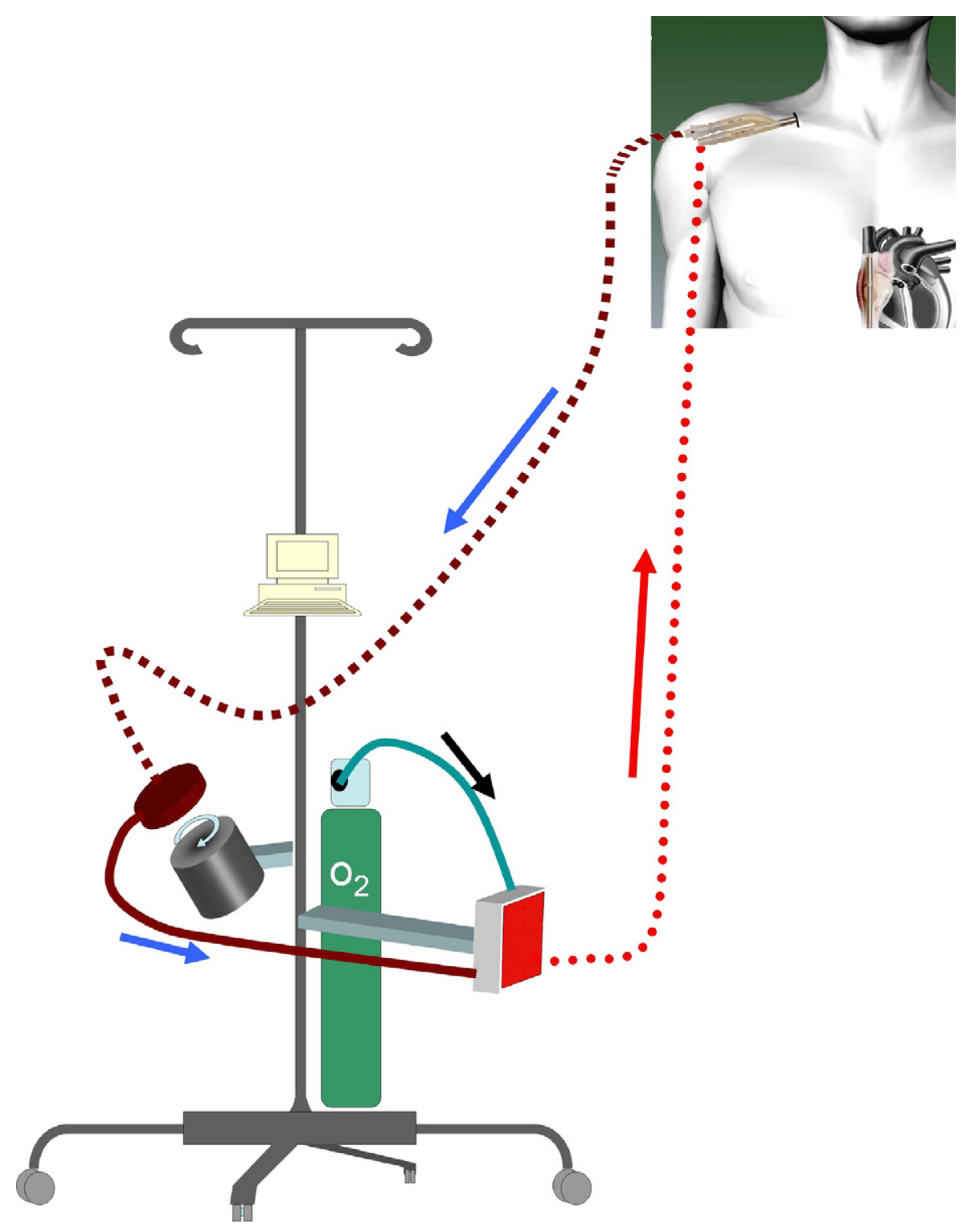

FIGURE 2. Ambulatory ECMO circuit.

with clearance of airway secretions. Of the 6 patients who were weaned from MV support, 3 were assisted to a chair for in-room rehabilitation, and 1 patient, who was treated primarily for unresponsive $\mathrm{CO}_{2}$ retention, underwent extensive rehabilitation, including treadmill walking. One patient with IPF and 1 patient with chronic obstructive pulmonary disease (COPD) were bridged to transplant, whereas $3 \mathrm{pa}-$ tients with acute respiratory distress syndrome and 1 patient with pulmonary arterial hypertension (PAH) were successfully bridged to recovery.

\section{Major Complications}

A major bleeding event was observed in 4 of the patients with a mean packed red blood cell use of 48.75 (19-118) units (Table 5). In 1 early patient, the bleeding event was secondary to a right atrial perforation that occurred during cannula positioning with echocardiographic guidance alone, and required operative repair. Two patients required

TABLE 3. Extracorporeal membrane oxygenation variables

\begin{tabular}{lc}
\hline \multicolumn{1}{c}{ Cannula size } & \\
\hline $23 \mathrm{~F}$ & 2 \\
$29 \mathrm{~F}$ & 1 \\
$31 \mathrm{~F}$ & 7 \\
$\mathrm{ECMO}$ duration (d) & $20 \pm 15$ \\
Flow $(\mathrm{L} / \mathrm{min})$ & $3.5(1.6-4.9)$ \\
$\mathrm{CO}_{2}$ removal (mL/min) & $228(54-570)$ \\
$\mathrm{O}_{2}$ transfer $(\mathrm{mL} / \mathrm{min})$ & $127(36-529)$ \\
\hline Variables are represented as $\mathrm{N}$, mean \pm standard deviation, or mean and (range).
\end{tabular}


TABLE 4. Outcomes

\begin{tabular}{|c|c|c|c|c|c|c|c|c|c|}
\hline $\begin{array}{c}\text { Patient } \\
\text { no. }\end{array}$ & $\begin{array}{c}\text { MV support on } \\
\text { ECMO duration (d) }\end{array}$ & Tracheostomy & $\begin{array}{c}\text { Out-of-bed } \\
\text { rehabilitation }\end{array}$ & $\begin{array}{l}\text { ICU } \\
\text { LOS }\end{array}$ & $\begin{array}{c}\text { Hospital } \\
\text { LOS }\end{array}$ & $\begin{array}{c}\text { 30-d } \\
\text { mortality }\end{array}$ & Transplanted & $\begin{array}{c}1-y \\
\text { mortality }\end{array}$ & $\begin{array}{c}1-y \\
\text { outcome } \\
\end{array}$ \\
\hline 1 & 12 & $\mathrm{~N}$ & - & 12 & 12 & $\mathrm{Y}$ & - & $\mathrm{Y}$ & Death \\
\hline 2 & 12 & $\mathrm{Y}$ & $\mathrm{Y}$ & 25 & 47 & - & $\mathrm{Y}$ & - & Home \\
\hline 3 & 9 & $\mathrm{~N}$ & - & 9 & 9 & $\mathrm{Y}$ & - & $\mathrm{Y}$ & Death \\
\hline 4 & 36 & $\mathrm{Y}$ & - & 69 & 72 & - & - & - & Home \\
\hline 5 & 2 & $\mathrm{~N}$ & $\mathrm{Y}$ & 25 & 25 & - & $\mathrm{Y}$ & $\mathrm{Y}$ & Death* \\
\hline 6 & 25 & $\mathrm{~N}$ & - & 25 & 25 & $\mathrm{Y}$ & - & $\mathrm{Y}$ & Death \\
\hline 7 & 20 & $\mathrm{Y}$ & - & 40 & 42 & _ & - & - & Home \\
\hline 8 & 9 & $\mathrm{Y}$ & $\mathrm{Y}$ & 40 & 40 & - & - & $\mathrm{Y}$ & Death \\
\hline 9 & 30 & $\mathrm{~N}$ & - & 30 & 30 & $\mathrm{Y}$ & - & $\mathrm{Y}$ & Death \\
\hline 10 & 9 & $\mathrm{~N}$ & $\mathrm{Y}$ & 37 & 37 & - & - & - & Home \\
\hline
\end{tabular}

ICU and hospital LOS include only post-ECMO. LOS, Length of stay. *Sepsis, after bilateral lung transplantation.

reintubation because of severe epistaxis and endobronchial bleeding, and 1 patient had a significant gastrointestinal bleed. All patients who received a tracheostomy $(\mathrm{N}=2)$ while receiving ECMO support and, therefore, anticoagulation therapy, had some surgical site bleeding. This was not observed in patients who "prophylactically" received a tracheostomy before ECMO support $(\mathrm{N}=2)$.

Two patients had a stroke. Both patients had known atrial septal defects, and presumably experienced a paradoxical embolic stroke. Full recovery was seen in one of them. Thirty-day mortalities were secondary to sepsis with multiorgan system failure $(\mathrm{N}=3)$ and after withdrawal of care by family once significant renal failure developed in a patient $(\mathrm{N}=1)$.

\section{DISCUSSION}

The present study attempted to improve the standard VV ECMO support for patients with severe pulmonary failure by using a single cannula system to allow minimal MV support and aggressive rehabilitation. In this initial experience, 6 of the 10 patients were successfully weaned from MV while supported with ECMO and bridged to recovery or transplantation. Of those 6 patients, 4 were able to meaningfully participate in active rehabilitation.

\section{TABLE 5. Major complications}

\begin{tabular}{ll}
\hline Major bleeding event & 4 \\
Right atrial perforation & 1 \\
Epistaxis/endobronchial bleed & 2 \\
GI bleed & 1 \\
Cannula-related infection & 0 \\
HITT & 1 \\
CVA & 2 \\
30-d mortality & 4 \\
Sepsis with MSOF & 3 \\
Family withdrawal of care & 1 \\
\hline
\end{tabular}

Variables are represented as N. GI, Gastrointestinal; HITT, heparin-induced thrombocytopenia and thrombosis; $C V A$, cerebrovascular accident; $M S O F$, multisystem organ failure.
The rationale for our ambulatory ECMO strategy emphasizing ambulation was to minimize deconditioning and ventilator-associated morbidity. There is sufficient evidence that patients confined to bed in an ICU setting undergo significant neuromuscular degeneration, ${ }^{8}$ and weakness of the large proximal and respiratory muscle leads to prolonged ventilation. ${ }^{9}$ Several studies have suggested that early ambulation is advantageous for patients in the ICU. In one prospective cohort study, an early mobilization protocol resulted in fewer days in bed, shorter ICU length of stay (5.5 vs 6.9 days), and decreased overall hospital length of stay (11.2 vs 14.5 days). ${ }^{10}$ In a recent randomized controlled trial, early activity led to fewer days of delirium and less time on a ventilator. ${ }^{11}$ Taken together, these studies imply that early activity may lead to improved outcomes in patients in the ICU. This is particularly important for lung transplantation candidates, in whom there is a direct correlation between functional status and exercise capacity with outcomes. ${ }^{12}$ Although rehabilitation while on MV has been reported, ${ }^{13}$ its use in patients requiring significant MV support while at rest is not a realistic goal. Also, rehabilitation while on MV has not been shown to reduce the risk of ventilator-induced lung injury, for which there is ample literature on its detriment to pulmonary recovery. ${ }^{14-17}$ In our cohort, the mean length of intubation and MV before ECMO support was 10 days. Many of these patients may have already had significant physical deconditioning and ventilator-induced lung injury. Perhaps earlier implementation of ECMO in these patients may be necessary to improve outcomes, and large randomized trials are critically needed in this area.

Several important lessons were learned from our early experience. As expected, patient selection seems to be one of the most central drivers of outcome. This was a diverse patient cohort with multiple causes of pulmonary failure. Patients with pneumonia/acute respiratory distress syndrome fared best, with 3 of 4 surviving to 1 year. Outcomes were poor in patients with IPF. Three of 4 patients died while awaiting transplantation, with a mean ECMO 
support of 18 (9-30) days. The other patient with IPF died of sepsis 2 months after bilateral lung transplantation. Significant right ventricular failure developed in the patients with IPF, and, despite adequate ECMO flows, they had progressive and rapid hypotension and hypoxia. This concurs with previous reports of dismal outcomes for patients with IPF once they require MV. ${ }^{18-20}$ In contrast, 2 patients of interest in this cohort, previously described, were one with $\mathrm{COPD}^{21}$ and one with $\mathrm{PAH}^{22}$ The patient with COPD was an extreme example of that disease process. He was unable to maintain a $\mathrm{PCO}_{2}$ of less than 100 $\mathrm{mm} \mathrm{Hg}$ unless fully sedated, despite tracheostomy and maximal MV. After ECMO initiation, his $\mathrm{PCO}_{2}$ was corrected, and the patient was able to participate in full cardiopulmonary rehabilitation before successful transplantation. At the time of referral for ECMO, the patient with PAH was severely hypoxic and acute right ventricular failure had developed, associated with an akinetic and "smoke-filled" echocardiogram. Normally, veno-arterial ECMO would be the ECMO strategy of choice for this case. However, the patient had a large atrial septal defect and preferential shunting of right atrial blood to the left atrium. By placing the dual-lumen cannula with the outflow orifice juxtaposed to the atrial septal defect, we successfully delivered fully oxygenated blood to the left atrium. This permitted adequate left-sided preload and provided shock-reversing oxygenation. Soon the distressed right ventricle improved and progressively could power venous return through the lungs. The patient recovered with the addition of pharmacologic therapies for PAH. The success of this patient may be an important stepping stone for other patient populations with right ventricular failure, such as our morbid patients with IPF.

There were 2 major changes in the technique of ECMO cannula insertion. The first was the consistent use of both transesophageal echocardiography and fluoroscopy during insertion. This was changed after advancement of the cannula "blindly" led to a right atrial perforation requiring operative intervention. There was no incidence of postinsertion cannula perforation or malpositioning with patient movement, as has been anecdotally described at other centers. We ascribe this to the tunneling of the cannula to hub the "Y" portion, diminishing advancement or withdrawal. The second technique change was in the tunneling itself. Although a subclavicular lay of the cannula would be ergonomic for patient mobility, after the first insertion, an intermittent, positional kinking of the cannula was noted. Subsequently, supraclavicular tunneling of the catheter was used, which avoided kinking but still offered an ergonomic lay. All subsequent patients had similar insertions with only varying cannula size based on presumed need of ventilation versus oxygenation.

A tracheostomy was required in 4 of the 6 patients weaned from mechanical ventilatory support. Tracheostomy both increased patient comfort during the MV weaning process and allowed for better pulmonary toilet. It is still unclear, however, which patients will ultimately require a tracheostomy with ECMO support. Nevertheless, on the basis of this small experience, patients with already prolonged ventilation or particularly severe disease may benefit from the tracheostomy being performed before the initiation of ECMO and anticoagulation.

Obtaining a balance between circuit and systemic thrombosis and hemorrhage in ECMO-supported patients is one of the most difficult and frustrating management issues. We observed almost universal endobronchial bleeding, which was major in 2 patients. In addition to careful titration of anticoagulation, diligent monitoring of fibrinogen levels and platelet function (thromboelastography and platelet function assay) has become mandatory to avoid these significant episodes. Additional simple considerations, including the use of low suction and red rubber catheters for naso-oropharyngeal and endotracheal clearance, have also reduced their incidence.

\section{Limitations}

The current series has limitations. It is small, retrospective, and descriptive; and the end point of extubation and ambulation was not met by all the patients. We believe few will argue the rationale for developing a strategy of progressive rehabilitation in the previously bed- and ventilator-bound ECMO-supported patient. The lessons we have learned are important not only for our own program but for those pursuing ECMO for adult respiratory support.

\section{CONCLUSIONS}

Further advancements in ECMO are required. The augmentation of ECMO with rehabilitation and minimal mechanical ventilatory support is feasible and may be beneficial in some patients. These early results, although promising, are only hypothesis generating and will require larger prospective trials before this strategy should receive widespread adoption.

\section{References}

1. Amato MBP, Barbas CSV, Medeiros DM, et al. Effect of a protective-ventilation strategy on mortality in the acute respiratory distress syndrome. $N$ Engl J Med. 1998;338:347-54.

2. Rossaint R, Falke KJ, Lopez F, et al. Inhaled nitric oxide for the adult respiratory distress syndrome. N Engl J Med. 1993;328:399-405.

3. Peek GJ, Moore HM, Moore N, Sosnowski AW, Firmin RK. Extracorporeal membrane oxygenation for adult respiratory failure. Chest. 1997;112:759-64.

4. Hemmila MR, Rowe SA, Boules TN, et al. Extracorporeal life support for severe acute respiratory distress syndrome in adults. Ann Surg. 2004;240:595-605.

5. Lindén V, Palmér K, Reinhard J, et al. High survival in adult patients with acute respiratory distress syndrome treated by extracorporeal membrane oxygenation, minimal sedation, and pressure supported ventilation. Intensive Care Med. 2000; 26:1630-7.

6. Good Peek GJ, Mugford M, Tiruvoipati R, et al, CESAR trial collaboration. Efficacy and economic assessment of conventional ventilator support versus extracorporeal membrane oxygenation for severe adult respiratory failure (CESAR): a multicentre randomised controlled trial. Lancet. 2009;374:1351-63. 
7. Bermudez CA, Rocha RV, Sappington PL, Toyoda Y, Murray HN, Boujoukos AJ. Initial experience with single cannulation for venovenous extracorporeal oxygenation in adults. Ann Thorac Surg. 2010;90:991-5.

8. De Jonghe B, Lacherade JC, Durand MC, Sharshar T. Critical illness neuromuscular syndromes. Crit Care Clin. 2007;23:55-69.

9. de Jonghe B, Lacherade JC, Sharshar T, Outin H. Intensive care unit-acquired weakness: risk factors and prevention. Crit Care Med. 2009;37:S309-15.

10. Morris PE, Goad A, Thompson C, et al. Early intensive care unit mobility therapy in the treatment of acute respiratory failure. Crit Care Med. 2008;36:2238-43.

11. Schweickert WD, Pohlman MC, Pohlman AS, et al. Early physical and occupational therapy in mechanically ventilated, critically ill patients: a randomised controlled trial. Lancet. 2009;373:1874-82.

12. Thabut G, Ravaud P, Christie JD, et al. Determinants of the survival benefit of lung transplantation in patients with chronic obstructive pulmonary disease. Am J Respir Crit Care Med. 2008;177:1156-63.

13. Schweickert WD, Pohlman MC, Pohlman AS, et al. Early physical and occupational therapy in mechanically ventilated, critically ill patients: a randomised controlled trial. Lancet. 2009;373:1874-82.

14. Gattinoni L, Carlesso E, Cadringher P, Valenza F, Vagginelli F, Chiumello D. Physical and biological triggers of ventilator-induced lung injury and its prevention. Eur Respir J. 2003;47:15s-25s.

15. Parker JC, Townsley MI, Rippe B, Taylor AE, Thigpen J. Increased microvascular permeability in dog lungs due to high peak airway pressures. J Appl Physiol. 1984;57:1809-16.

16. Pinhu L, Whitehead T, Evans T, Griffiths M. Ventilator-associated lung injury. Lancet. 2003;361:332-40.

17. Ricard JD, Dreyfuss D, Saumon G. Ventilator-induced lung injury. Eur Respir J. 2003;42:2s-9s.

18. Mollica C, Paone G, Conti V, et al. Mechanical ventilation in patients with end-stage idiopathic pulmonary fibrosis. Respiration. 2010;79:209-15.

19. Stern JB, Mal H, Groussard O, et al. Prognosis of patients with advanced idiopathic pulmonary fibrosis requiring mechanical ventilation for acute respiratory failure. Chest. 2001;120:213-9.

20. Mallick S. Outcome of patients with idiopathic pulmonary fibrosis (IPF) ventilated in intensive care unit. Respir Med. 2008;102:1355-9. Epub 2008 Jul 17.

21. Garcia JP, Iacono A, Kon ZN, Griffith BP. Ambulatory extracorporeal membrane oxygenation: a new approach for bridge-to-lung transplantation. J Thorac Cardiovasc Surg. 2010;139:e137-9.

22. Srivastava MC, Ramani GV, Garcia JP, Griffith BP, Uber PA, Park MH. Venovenous extracorporeal membrane oxygenation bridging to pharmacotherapy in pulmonary arterial hypertensive crisis. J Heart Lung Transplant. 2010;29:811-3.

\section{Discussion}

Dr Mark Danton (Glasgow, Scotland). We have had experience with this cannula in neonates and have been concerned about the incidence of perforation. One case occurred at implantation, as you have had, but another case occurred late down the line when the patient was having physiotherapy on the lungs. The cannula was well placed at the time of implantation with the distal end in the inferior vena cava but had subsequently migrated, and with the physiotherapy and the up and down movement had caused a right atrial perforation and required repair. So my question to you is that once you have positioned these catheters, cannulas, do you subsequently monitor their position and review their position, particularly when you are starting to mobilize the patient?

Dr Kon. In our experience, we only had a single perforation. It was during cannula placement, and that, again, was before fluoroscopy and transesophageal echocardiography were used in every case for placement. In regard to movement of the cannula during physiotherapy, we routinely tunnel our catheter so it is actually hubbed at the end of the tunnel and secured at that point with multiple sutures. We then monitor its placement with daily chest $\mathrm{x}$-rays, which seemed to have worked, and we haven't had any cannula dislodgement or movement.

Dr Thoralf Sundt (Rochester, Minn). Patients with pulmonary hypertension are a problem for a lot of us, and that is where we see the need for ECMO frequently in bridging to transplant. I am a little confused. Can you help me understand how a VV system helps you deal with pulmonary hypertension? Usually their mode of exit is right heart failure.

Dr Kon. That patient actually had a wide open atrial septal defect, and I guess you could consider it pseudo-venoarterial ECMO in that patient, because with that central orifice in the right atrium, it essentially just flows right across into the left atrium, thereby bypassing the lungs.

Dr Bryan Meyers (St Louis, Mo). This is a type of therapy that is currently in use for other indications, and what you are proposing in addition to the new technology or the specific technology is extending the indications, and it is based on an assessment of the patient's poor prognosis. I think in other areas we have objective risk scores. You have 2 intensivists who assure you that the prognosis is poor, but in assessing the value of something like this, it would be nice to have some objective estimate of that patient's prognosis to know what difference you have made when all is said and done.

Dr Kon. Thank you for the comment. I agree completely.

Dr Bansi Koul (Lund, Sweden). Thanks for a wonderful presentation and excellent results. My short question to you is about what I observed from your data that you have increasingly been using $31 \mathrm{~F}$ cannulas, especially in the later part of your experience. Was it because the blood flows were not sufficient to oxygenate the patient or can you give us some information idea about the extracorporeal recirculation of the oxygenated blood within this setup?

Dr Kon. We did use 31F routinely toward the end of this cohort, and it was in fact because it is hard to get flows up to 4 liters with these smaller cannulas, and we had minimal to no recirculation in this circuit, because the fenestrations sit in the inferior and superior venae cavae and then the outflow is directly toward the tricuspid valve. 